\title{
PENGUKURAN INDEKS ULTRAVIOLET MATAHARI DAN ATENUASINYA OLEH BEBERAPA BAHAN UNTUK REKOMENDASI WAKTU AMAN BERJEMUR
}

\author{
Sigit Ristanto ${ }^{1, \star}$, Choirul Huda ${ }^{1}$, dan Affandi Faisal Kurniawan ${ }^{1}$ \\ ${ }^{1}$ Prodi Pendidikan Fisika, Fakultas MIPATI, Universitas PGRI Semarang, Semarang \\ *sigitristanto@upgris.ac.id
}

Received 02-07-2021, Revised 20-08-2021, Accepted 07-09-2021, Published 01-10-2021

\begin{abstract}
Research has been carried out on the measurement of the sun's ultraviolet (UV) index and its attenuation by several materials. This research was motivated by the need to bask in the hot sun as an effort to increase the body's immune system amid the Covid-19 Pandemic. The ultraviolet index is the key in determining the right time. This study aims to obtain data on the distribution of the UV index in an area and its attenuation for the purpose of recommending a safe time for sunbathing. The measuring instrument used is an analog UV index sensor that converts UV radiation into analog voltage in the range $0-1 \mathrm{~V}$. The output value is read using a multimeter and then converted into UV index using the product's built-in conversion table. The UV index measurement is divided into three conditions, first based on the time range from $08.00-16.00 \mathrm{WIB}$, the effect of cloud cover, and the UV index measurement when passing through several materials: transparent glasses, ribbed glasses, plastic packaging, hats, and sports t-shirts. The results showed that the distribution of the UV index based on the time span was successfully obtained, cloud cover caused a decrease in the UV index by 4 levels and the attenuation of the UV index by several materials was obtained. Based on the sample data collection in Tinjomoyo Banyumanik, Semarang City, the safe time for sunbathing is in the range before $10.00 \mathrm{WIB}$ and after $14.00 \mathrm{WIB}$.
\end{abstract}

Keywords : UV index, ultraviolet protection, sun safe, solar radiation.

\section{ABSTRAK}

Telah dilakukan penelitian tentang pengukuran indeks ultraviolet (UV) matahari dan atenuasinya oleh beberapa bahan. Penelitian ini dilatarbelakangi oleh kebutuhan berjemur di tengah terik matahari sebagai upaya meningkatkan imun tubuh ditengah Pandemi Covid-19. Indeks ultraviolet menjadi kunci dalam menentukan waktu yang tepat. Penelitian ini bertujuan memperoleh data distribusi indeks UV di suatu wilayah beserta atenuasinya untuk keperluan rekomendasi rentang waktu aman berjemur. Alat ukur yang digunakan berupa sensor indeks UV analog yang mengubah radiasi UV menjadi tegangan analog pada rentang $0-1 \mathrm{~V}$. Nilai output dibaca menggunakan multimeter lalu dikonversi ke dalam UV indeks menggunakan tabel konversi bawaan produk. Pengukuran UV indeks dibagi menjadi tiga kondisi, pertama berdasarkan rentang waktu pada rentang waktu dari pukul 08.00 - 16.00 WIB, pengaruh tutupan awan, dan pengukuran UV indeks saat melawati beberapa bahan: kacamata transparan, kacamata riben, plastik kemasan, topi, dan kaos olahraga. Hasil penelitian menunjukkan distribusi indek UV berdasarkan rentang waktu berhasil diperoleh, tutupan awan menyebabkan penurunan indek UV sebesar 4 tingkat dan atenuasi Indek UV oleh beberapa bahan berhasil diperoleh. Berdasarkan sampel pengambilan data di Tinjomoyo Banyumanik Kota Semarang diperoleh waktu aman berjemur berada pada rentang sebelum Pukul 10.00 WIB dan setelah Pukul 14.00 WIB.

Kata kunci: indeks UV, proteksi ultraviolet, aman berjemur, radiasi matahari . 


\section{PENDAHULUAN}

Penelitian ini dilatarbelakangi oleh Pandemi Covid-19 yang telah menyita perhatian seluruh dunia. Salah satu upaya pencegahan yang dianjurkan adalah peningkatan imun tubuh melaui berjemur di bawah terik Matahari yang mengandung ultraviolet (UV) B. Sinar ini berperan besar dalam pembentukan vitamin D3 sebagai penguat imun tubuh.

Namun demikian, berjemur di bawah terik matahari langsung mengandung resiko. Indeks UV menunjukkan skala resiko paparan radiasi ultraviolet matahari. Berdasarkan resikonya Indek UV dikategorikan menjadi lima yaitu rendah $(0-2)$, sedang $(3-5)$, tinggi $(6-7)$, sangat tinggi $(8-10)$, ekstrim $(>11)^{[1]}$.

Penelitian tentang pengaruh paparan ultraviolet telah banyak dilakukan. Yosephin ${ }^{[2]}$ telah meneliti peranan ultraviolet B sinar Matahari terhadap vitamin D dan tekanan darah wanita usia subur. Paparan dilakukan pada wajah dan lengan selama 30 menit tiga kali seminggu hingga 12 minggu. Hasil penelitiannya menunjukkan adanya peningkatan Vitamin D sebesar $15,9 \%$. Demikian juga, Rimahardhika ${ }^{[3]}$ telah meneliti perbedaan asupan vitamin D orang yang bekerja di dalam ruangan dan di luar ruangan. Hasil penelitiannya menunjukkan asupan vitamin D orang yang bekerja diluar ruangan lebih tinggi dibanding yang bekerja di dalam ruangan. Di lain sisi Fitria ${ }^{[4]}$ telah menunjukkan paparan sinar matahari dapat meningkatkan kepadatan massa tulang dan menurunkan kadar kolesterol darah, sedangkan Wahyuni ${ }^{[5]}$ telah menunjukkan bahwa sinar matahari juga dapat menurunkan tekanan darah pada pasien hipertensi.

Sementara itu, ultraviolet $\mathrm{C}$ membawa dampak buruk. Makiyah ${ }^{[6]}$ telah meneliti pengaruh paparan ultraviolet $\mathrm{C}$ terhadap diameter pulpa alba limpa dan indek mitotik epidermis kulit mencit. Paparan 15 menit dua kali sehari selama 15 hari telah menunjukkan ada pengaruh signifikan. Hal ini selaras dengan yang dilakukan oleh Andani ${ }^{[7]}$ dan Rini ${ }^{[8]}$.

Mendes $^{[9]}$ telah meneliti kadar vitamin D masyarakat di Brasil. Dari segi paparan matahari Negara tersebut termasuk Negara tropis dengan paparan matahari yang melimpah. Namun, mayoritas masyarakat di Brasil kekurangan Vitamin D. Hasil penelitian tersebut menunjukkan bahwa paparan sinar matahari yang melimpah belum tentu berkorelasi positif dengan kadar vitamin D masyarakatnya.

Buyukuslu $^{[10]}$ telah meneliti pengaruh gaya pakaian terhadap kadar vitamin D di Istanbul. Ia membandingkan wanita yang berbusana terbuka dengan wanita muslim yang berbusana tertutup. Hasil penelitannya menunjukkan bahwa kadar vitamin D wanita berbusana terbuka lebih banyak memiliki kadar vitamin D. Penelitian ini menunjukkan bahwa gaya pakaian mempengaruhi serapan radiasi ultraviolet sinar matahari.

Fiannisa $^{[11]}$ telah meneliti perbedaan kadar vitamin D berdasarkan durasi paparan sinar matahari. Ia membandingkan paparan matahari pada durasi 15 menit dan 30 menit terhadap produksi vitamin D dalam tubuh. Hasil penelitiannya menunjukkan bahwa tidak terdapat paparan yang signifikan antara keduanya. Dengan demikian berjemur 15 menit dibawah matahari langsung sudah cukup untuk meningkatkan produksi vitamin $\mathrm{D}$ dalam tubuh.

Metode proteksi sinar UV dengan bahan pakaian diuraikan sebagai berikut. Rachman ${ }^{[12]}$ telah meneliti aplikasi partikel nano seng oksida pada kain batik zat warna alam secang untuk meningkatkan proteksi warna terhadap radiasi ultraviolet. Hasil penelitiannya menunjukkan bahwa bahan tersebut memiliki nilai proteksi UV sebesar 15,08 sehingga masuk dalam kategori anti UV. Tabir surya dari berbagai bahan telah dikembangkan 
seperti: krim ekstrak buah naga ${ }^{[13]}$, ekstrak bawang hitam ${ }^{[14]}$, ekstrak spirulina ${ }^{[15]}$, daun mengkudu ${ }^{[16]}$, gel Kitosan ${ }^{[17]}$, kombinasi ekstrak daun ketepeng dan binahong ${ }^{[18]}$, ekstrak daun Kitolod ${ }^{[19]}$, ekstrak bekatul padi ${ }^{[20]}$, dan ekstrak daun gaharu $^{[21]}$.

Berdasarkan latar belakang tersebut penelitian ini fokus pada pengukuran Indeks UV. Proses pengukuran dibagi menjadi tiga ketegori yaitu berdasarkan rentang waktu (dari pukul 08.00 - $16.00 \mathrm{WIB}$ ), pengaruh tutupan awan, dan pengaruh tutupan bahan terdiri atas: kacamata transparan, kacamata riben, plastik, topi, dan kaos olahraga. Melalui pengukuran ini diharapkan diperoleh data distribusi indeks UV sehingga dapat dijadikan sebagai dasar rekomendasi waktu aman berjemur.

\section{METODE}

Alat yang digunakan dalam penelitian ini antara lain sensor indek ultraviolet, project board, multimeter, dan baterai. Spesifikasi sensor ditunjukkan pada Tabel 1. Bahan yang digunakan antara lain kacamata transparan, kacamata riben, plastic kemasan, topi, dan kaos olahraga.

Tabel 1. Skema sensor indeks UV

\begin{tabular}{ll}
\hline No & Spesifikasi \\
\hline 1 & IC Boost Converter : SGM8521 \\
2 & Tegangan Kerja : 3 - 5,5 (Volt) \\
3 & Tipe Output : TTL level output \\
4 & Panjang Gelombang Response : $200-370(\mathrm{~nm})$. \\
5 & Vcc = 3,3 - 5 (volt) \\
6 & GND = Ground catu daya \\
7 & Aout = MCU I/O (analog output) rentang $0-1 \mathrm{~V}$ \\
8 & Akurasi = 1 indeks UV \\
\hline
\end{tabular}

Rangkaian alat ukur ditunjukkan pada Gambar 1. Sensor SGM8521 memiliki tiga kaki yaitu Ground (-), Anoda(+), dan $\mathrm{V}_{\text {out. }}$ Sensor dipasang pada project board lalu kaki Ground dan Anoda dihubungkan dengan tiga buah baterai AAA masing-masing memiliki tegangan 1,5 volt yang dirangkai seri sehingga memenuhi tegangan kerja. Selanjutnya sisi positif multimeter dihubungkan dengan kaki $\mathrm{V}_{\text {out }}$ sensor sedangkan kaki negatifnya dihubungkan dengan ground sensor. Probe multimeter di atur pada tegangan DC 0,5 volt atau DC 2,5 volt bergantung besar kecilnya tegangan $\mathrm{V}_{\text {out. }}$

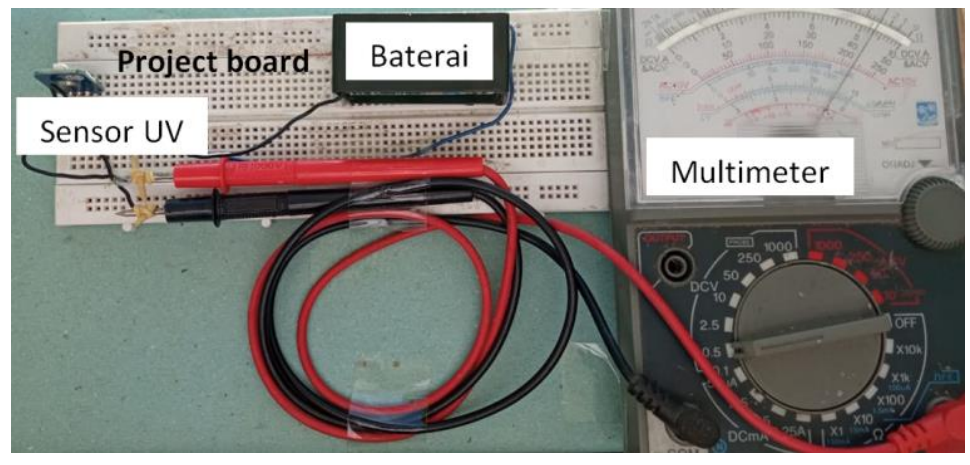

Gambar 1. Rangkaian alat ukur

Hasil nilai output tegangan yang terbaca pada multimeter dikonversi menjadi indeks UV menggunakan Tabel 2. Tabel 2 merupakan hasil kalibrasi bawaan produsen sensor. 
Tabel 2. Konversi tegangan output $\left(\mathrm{V}_{\text {Out }}\right)$ ke indeks UV

\begin{tabular}{lcccccccccccc}
\hline Vout $(\mathbf{m V})$ & $<50$ & 227 & 318 & 408 & 503 & 606 & 696 & 795 & 881 & 976 & 1079 & $1170+$ \\
Indeks UV & 0 & 1 & 2 & 3 & 4 & 5 & 6 & 7 & 8 & 9 & 10 & $11+$ \\
\hline
\end{tabular}

\section{HASIL DAN PEMBAHASAN}

1. Pengukuran indeks UV berdasarkan rentang waktu

Pengukuran indeks UV berdasarkan rentang waktu dilakukan pada pukul $08.00-16.00$ WIB, tanggal 13 Juni 2021. Lokasi yang dipilih adalah Tinjomoyo Banyumanik Semarang yang terletak pada -7,0367611 LU; 110,4136759 LS dengan ketinggian tanah $\pm 270 \mathrm{~m}$ dari permukaan laut. Hasil pengukuran indeks UV ditunjukkan pada Gambar 2.

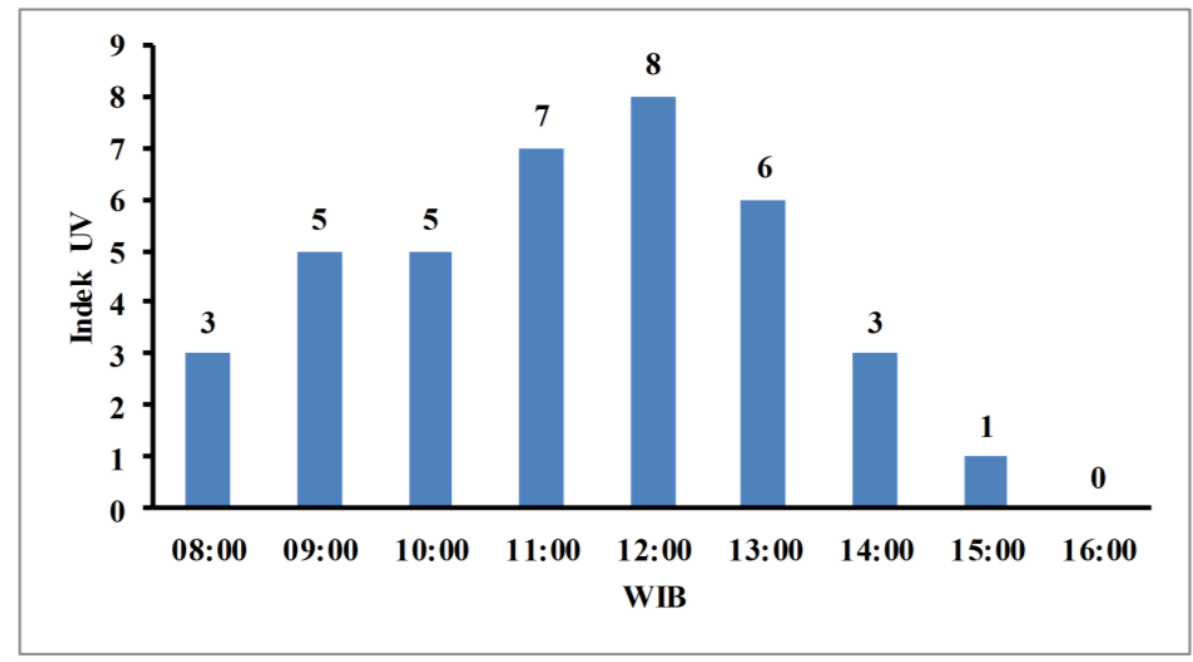

Gambar 2. Hasil ukur indeks UV pada pukul 08.00 - 16.00 WIB tanggal 13 Juni 2021 di Tinjomoyo Banyumanik Semarang

Berdasarkan Gambar 2 pada pukul 08.00 - 10.00 WIB indek UV masih berada pada rentang 3 sampai dengan 5. Pada jam ini resiko paparan matahari masih berada dalam tingkatan sedang. Namun, pada pukul $11.00-13.00$ WIB berada pada rentang 6 sampai dengan 8. Puncak tertinggi pada pukul 12.00 WIB. Pada rentang waktu ini resiko paparan matahari berada pada tingkatan tinggi. Selanjutnya pada Pukul 14.00 WIB kembali menunjukkan indeks UV 3 sehingga sudah kembali ke level sedang. Terakhir, pada Pukul 15.00 - 16.00 WIB telah berada pada rentang 0 sampai dengan 3. Pada rentang ini paparan matahari telah memasuki tingkatan rendah.

Berdasarkan data distribusi indeks UV pada Gambar 2, jika batasan jam tingkatan aman berjemur maksimal pada tingkatan indek UV sedang (3 - 5) maka dapat direkomendasikan rentang aman berjemur berada pada rentang saat matahari terbit hingga pukul 10.00 WIB dan mulai pukul 14.00 WIB sampai matahari terbenam.

\section{Pengaruh tutupan awan}

Indek UV di suatu daerah juga dipengaruhi oleh tutupan awan. Konsisi tutupan awan saat dilakukan pengukuran ditunjukkan pada gambar 3 (kiri) sedangakan hasil ukur pengaruh tutupan awan terhadap indek UV ditunjukkan pada gambar 3 (kanan). Pengukuran ini dilakukan pada rentang pukul 11.00 - 13.00 WIB. Pada saat cerah indek UV menunjukkan 
nilai 7. Beberapa saat kemudian matahari tertutup awan. Lalu hasil pembacaan alat ukur menunjukkan indek UV turun menjadi 3. Berdasarkan data ini tutupan awan dapat menurunkan indek UV hingga 4 tingkatan.
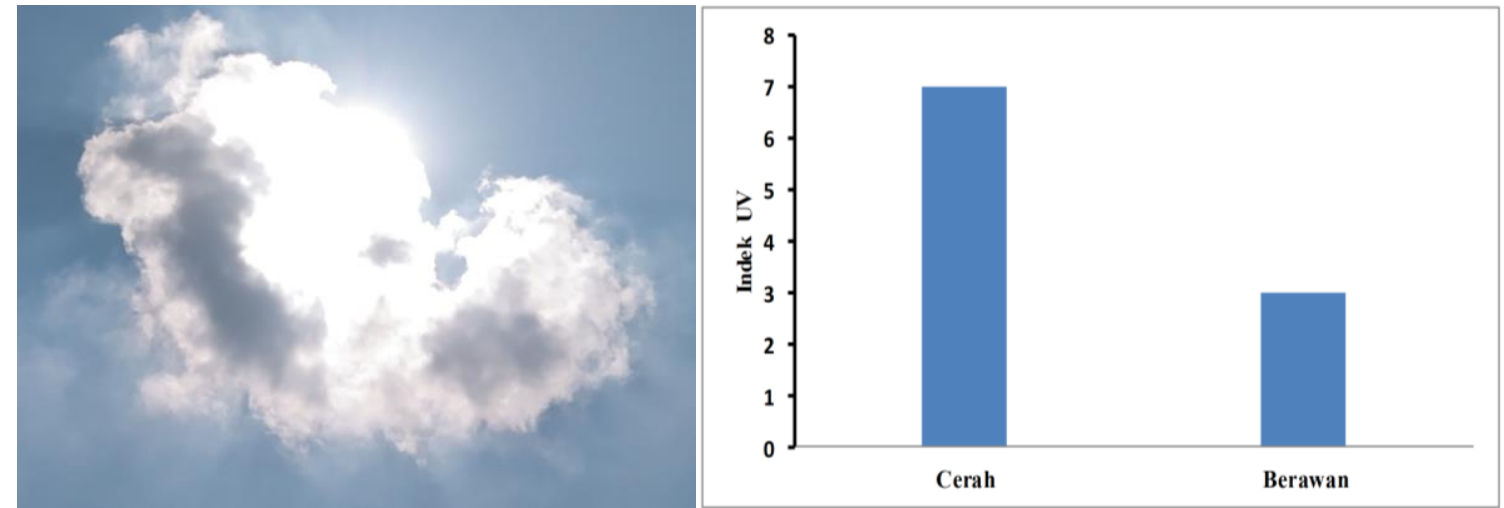

Gambar 3. Pengaruh tutupan awan terhadap indek UV

Berdasarkan data pada Gambar 3, pada pukul 11.00 - 13.00 WIB indeks UV berada pada level tinggi. Jika pada saat itu matahari tertutup awan indeks UV dapat turun menuju level sedang. Dengan demikian tutupan awan dapat mengurangi resiko terpapar matahari secara langsung.

\section{Pengukuran penyerapan/atenuasi UV oleh benda}

Pada bagian ini dibahas usaha menurunkan paparan ultra violet menggunakan penutup/filter. Untuk mengurangi paparan sinar matahari pada umumnya dan sinar ultra violet pada khususnya terdapat berbagai macam filter mulai dari tabir surya, pakaian, penutup kepala, kacamata, dan lain sebagainya.

Penelitian ini menggunakan kacamata transparan, kacamata riben, plastik kemasan, topi, dan kaos. Plastik kemasan dipilih karena terkait dengan makanan dalam kemasan yang terpapar langsung oleh matahari, sedangkan keempat bahan lainnya dipilih karena sering direkomendasikan untuk mengurangi resiko paparan matahari.

Pengukuran indek UV dilakukan pada saat matahari terik pada pukul 11.00 - $13.00 \mathrm{WIB}$. Proses pengukuran dilakukan dengan cara menempatkan penutup antara sinar matahari dengan sensor indek UV. Jenis penutup beserta output indek UV tanpa penutup dan dengan penutup disajikan pada Tabel 3.

Berdasarkan Tabel 3 kacamata riben dan topi dapat menurunkan indeks UV paling besar yaitu sebesar 7 tingkatan. Urutan kedua ditempati kacamata transparan dan kaos olahraga sebesar 6 tingkatan. Penurunan paling kecil ditempati oleh plastik kemasan sebesar 1 tingkatan. Dengan demikian kacamata transparan, kacamata riben, topi dan kaos olahraga aman digunakan untuk melindungi tubuh dari paparan matahari secara langsung. Sedangkan plastik kemasan tidak signifikan menurunkan indeks UV. Dengan demikian, metode pengawetan makanan dengan penyinaran sinar UV dapat dilakukan walaupun makanan berada dalam kemasan. 
Tabel 3. Atenuasi indes UV oleh beberapa bahan pada pukul $11.00-11.30$ WIB

\begin{tabular}{|c|c|c|c|}
\hline No & Penutup & $\begin{array}{l}\text { Indeks UV tanpa } \\
\text { penutup }\end{array}$ & $\begin{array}{l}\text { Indeks UV dengan } \\
\text { penutup }\end{array}$ \\
\hline 1 & Kacamata transparan & 7 & 1 \\
\hline 2 & a riben & 7 & 0 \\
\hline 3 & masan & 7 & 6 \\
\hline 4 & Top & 7 & 0 \\
\hline 5 & 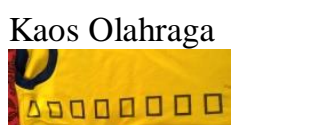 & 7 & 1 \\
\hline
\end{tabular}

\section{KESIMPULAN}

Berdasarkan hasil pengukuran yang telah dilakukan dapat disimpulkan bahwa waktu aman berjemur di wilayah tinjomoyo Banyumanik Semarang dilakukan saat matahari terbit hingga pukul $10.00 \mathrm{WIB}$ dan setelah pukul $14.00 \mathrm{WIB}$ hingga matahari terbenam. Tutupan awan dapat menurunkan indeks UV tinggi ke sedang. Kacamata transparan, kacamata riben, topi dan kaos olahraga efektif menurunkan Indeks UV sehingga dapat digunakan untuk melindungi tubuh dari paparan matahari secara langsung. Plastik kemasan tidak signifikan menurunkan indeks UV.

\section{UCAPAN TERIMAKASIH}

Ucapan terima kasih kami sampaikan pada LPPM Universitas PGRI Semarang (UPGRIS) dan Laboratorium Pendidikan Fisika UPGRIS yang telah memfasilitasi terlaksananya penelitian ini.

\section{DAFTAR PUSTAKA}

1. https://www.bmkg.go.id/cuaca/indeks-uv.bmkg

2. Yosephin, B., Khomsan, A., Briawan, D. dan Rimbawan, R. 2014. Peranan Ultraviolet B Sinar Matahari terhadap Status Vitamin D dan Tekanan Darah pada Wanita Usia Subur. Kesmas: National Public Health Journal, 256-260.

3. Rimahardika, R. 2017. Asupan Vitamin D dan Paparan Sinar Matahari pada Orang yang Bekerja di Dalam Ruangan dan di Luar Ruangan. Disertasi, Universitas Diponegoro Semarang. 
4. Fitria, C. N. dan Prabowo, A. 2016. Efektifitas Paparan Ultra Violet Sinar Matahari Terhadap Kepadatan Massa Tulang Dan Kadar Kolesterol Pada Lansia. Profesi (Profesional Islam): Media Publikasi Penelitian, 14 (1), 1-4.

5. Wahyuni, S. E. dan Nurhidayat, S. 2019. Pengaruh Paparan Sinar Matahari Terhadap Penurunan Tekanan Darah Pada Pasien Hipertensi. In 1st Prosiding Seminar Nasional Fakultas Ilmu Kesehatan, 240-247.

6. Makiyah, S. N. N., Iszamriach, R. dan Nofariyandi, A. 2014. Paparan ultraviolet c meningkatkan diameter pulpa alba limpa dan indeks mitotik epidermis kulit mencit. Jurnal Kedokteran Brawijaya, 28 (1), 17-21.

7. Andani, R. L. dan Busman, H. 2014. Pengaruh Paparan Sinar Lampu Ultraviolet (UV) C terhadap Berat Organ dan Gambaran Histopatologi Hepar Mencit Jantan (Mus musculus 1.). Jurnal Majority, 3 (5).

8. Rini, A. S. dan Sibero, H. T. 2014. Pengaruh Intensitas Waktu Paparan Sinar Ultraviolet-C Terhadap Ketebala Kornea Mencit (Mus Musculus L.). Jurnal Majority, 3 (5).

9. Mendes, M. M., Hart, K. H., Botelho, P. B. dan Lanham-New, S. A. 2018. Vitamin D status in the tropics: Is sunlight exposure the main determinant?. Nutrition Bulletin, 43 (4), 428-434.

10. Buyukuslu, N., Esin, K., Hizli, H., Sunal, N., Yigit, P. dan Garipagaoglu, M. 2014. Clothing preference affects vitamin D status of young women. Nutrition research, 34 (8), 688-693.

11. Fiannisa, R. 2020. Perbedaan Kadar Vitamin D 25-Oh Berdasarkan Durasi Paparan Sinar Matahari. Skripsi. Universitas Lampung Bandar lampung.

12. Rachman, A. F., Widodo, M. dan Sugiyana, D. 2020. Aplikasi Partikel Nano Seng Oksida pada Kain Batik Zat Warna Alam Secang (Caesalpillina Sappan Linn) untuk Meningkatkan Proteksi Warna terhadap Radiasi Ultraviolet. In Prosiding Seminar Nasional Industri Kerajinan dan Batik, 2 (1), A12-A12.

13. Prasetya, I. P. D., Arijana, I. K. N., Linawati, N. M., Wayan, I., dan Sugiritama, I. 2020. Krim Ekstrak Kulit Buah Naga Super Merah (Hylocereus Costaricensis) Meningkatkan Kelembapan Kulit Tikus Wistar (Rattus Norvegicus) yang Dipapar Sinar Ultraviolet B. Jurnal Medika Udayana, 9 (11)11, 49-54.

14. Dampati, P. S. dan Veronica, E. 2020. Potensi Ekstrak Bawang Hitam sebagai Tabir Surya terhadap Paparan Sinar Ultraviolet. KELUWIH: Jurnal Kesehatan dan Kedokteran, 2 (1), 23-31.

15. Pratama, G. M., Hartawan, I. G. N., Indriani, I. G. A., Yusrika, M. U., Suryantari, S. A., dan Sudarsa, P. S. 2020. Potency of Spirulina platensis Extract as Sunscreen on Ultraviolet B Exposure. Journal of Medicine and Health, 2 (6).

16. Mugitasari, D. E. dan Rahmawati, B. 2020. Formulasi Krim Ekstrak Daun Mengkudu (Morinda Citrifolia L.) Sebagai Sediaan Pelindung Sinar Ultraviolet. Jurnal Keperawatan dan Kesehatan Masyarakat Cendekia Utama, 9 (2), 109-119.

17. Fahrezi, M. A., Nopiyanti, V. dan Priyanto, W. 2021. Formulasi dan Uji Aktivitas Tabir Surya Gel Kitosan Menggunakan Karbopol 940 dan HPMC K100 sebagai Gelling Agent. Jurnal Farmasi (Journal of Pharmacy), 10 (1), 17-23.

18. Lestari, I., Prajuwita, M. and Lastri, A. 2021. Penentuan Nilai SPF Kombinasi Ekstrak Daun Ketepeng dan Binahong Secara In Vitro. Parapemikir: Jurnal Ilmiah Farmasi, 10 (1), 1-10.

19. Savira, D. dan Iskandar, D. 2020. Pemanfaatan Ekstrak Daun Kitolod (Hippobroma Longiflora (L) G. Don) sebagai Bahan Aktif Sediaan Tabir Surya. Jurnal Kimia Riset, $5(1), 44-48$. 
20. Wijaya, I. R. I. dan Safitri, C. I. N. H. 2020. Uji Aktivitas Formulasi Lip Balm dari Ekstrak Bekatul Padi (Oryza sativa) sebagai Tabir Surya. Prosiding SNPBS (Seminar Nasional Pendidikan Biologi dan Saintek) Ke-5.

21. Sari, D. I., Rahmawanty, D. dan Humairo, S. R. I. S. A. 2020. Profil Perlindungan Sediaan Lotion Ekstrak Air Daun Gaharu (Aquillaria Microcarpa) terhadap Uv-A dan Uv-B. Prosiding Seminar Nasional Lingkungan Lahan Basah, 5 (1), 93-97. 